\title{
Retraction: Capturing carbon dioxide as a polymer from natural gas
}

\author{
Chih-Chau Hwang, Josiah J. Tour, Carter Kittrell, Laura Espinal, Lawrence B. Alemany \& James M. Tour
}

Nature Communications 5:3961 doi: 10.1038/ncomms4961 (2014); Published 3 Jun 2014; Updated 1 Nov 2016

In this Article, we reported the synthesis of nucleophilic sulfur- and nitrogen-containing porous carbons and their carbon dioxide uptake performance. Specifically, we described a mechanism where the carbon dioxide polymerized in the channels of the porous support. Since the publication of the Article we have been unable to reproduce the infrared, Raman and solid-state ${ }^{13} \mathrm{C}-\mathrm{NMR}$ spectra that supported this mechanism; these data had been generated in the laboratory of J.M.T. During our efforts to reproduce the infrared spectra, the band centred at $1,735 \mathrm{~cm}^{-1}$ was not as pronounced as in the published data. The Raman band at $798 \mathrm{~cm}{ }^{-1}$ was observed on the occasion but disappeared with further focusing of the instrument; and the 166.5 p.p.m. peak in the solid-state ${ }^{13} \mathrm{C}-\mathrm{NMR}$ could not be acquired again. While the gas adsorption data are without question and reproduced across laboratories, we are no longer confident in the spectroscopic data supporting the proposed carbon dioxide polymerization mechanism and we, the authors, therefore wish to retract this Article.

This work is licensed under a Creative Commons Attribution 4.0 International License. The images or other third party material in this article are included in the article's Creative Commons license, unless indicated otherwise in the credit line; if the material is not included under the Creative Commons license, users will need to obtain permission from the license holder to reproduce the material. To view a copy of this license, visit http://creativecommons.org/licenses/by/4.0/
}

(C) The Author(s) 2016 